\title{
EL POETA Y EL CRONISTA MODERNISTA EN EL PRÓLOGO AL "POEMA DEL NiÁGARA"*
}

\author{
THE POET AND THE MODERNIST WRITER \\ IN THE PROLOGUE OF "POEMA DEL NiÁGARA"
}

\section{JAIME GALGANI MUÑOZ}

\section{RESUMEN}

Este artículo propone una lectura detallada del prólogo que José Martí escribió para la obra de Juan Antonio Pérez Bonalde, "Poema del Niágara” (1882), con el propósito de profundizar en los fundamentos sobre los cuales descansa la producción literaria y periodística del escritor modernista latinoamericano. Se intenta responder a la pregunta fundamental del lugar del escritor en la modernidad, especialmente en el contexto de su participación en el espacio periodístico.

Palabras clave: Modernismo, modernidad, crónica modernista, periodismo, José Martí.

\section{ABSTRACT}

This article provides a detailed reading of the prologue that José Martí wrote for "Poema del Niágara" by Juan Antonio Pérez Bonalde (1882), in order to go deeper into the foundations on which the literary and journalistic production of the Latin American modernist writer rest. It attempts to answer the fundamental question of the writer's place in modernity, especially regarding his participation in the context of the journalistic space.

Keywords: Modernism, modernity, modernist chronic, journalism, José Martí.

Recibido: 05.06.15. Aceptado: 25.12.15.

\footnotetext{
* Artículo asociado a proyecto de investigación FONDECYT Regular 1130400, "La columna cultural de escritoras y escritores en la prensa chilena desde 1900-1920: aportes y transformaciones del género y de sus autores". Un extracto del mismo fue presentado en el I Seminario Internazionale di Studi su Letteratura e Giornalismo, Lucca - marzo de 2015.

** Doctor en Literatura. Universidad Metropolitana de Ciencias de la Educación (UMCE), Santiago, Chile. Correo electrónico: jaime.galgani@gmail.com
} 


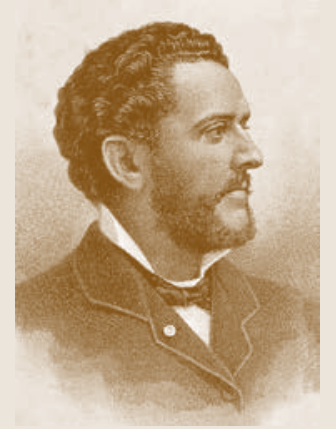

J. A. Pérez Bonalde
$\mathrm{E}$ L PRÓLOGO DE José Martí al "Poema del Niágara”" -más conocido y comentado que el mismo poema de Juan Antonio Pérez Bonalde- resulta imprescindible para revisar las relaciones entre el escritor (entendido como profesional de las letras) y la modernidad latinoamericana. En efecto, la modernidad, entendida aquí como el proceso que surge con el humanismo tardo medieval que da paso al Renacimiento y que se refuerza activamente con la valoración de la razón ilustrada, en los siglos XVII y XVIII, y con el desarrollo de la racionalidad técnico-científica en el siglo XIX (Habermas, Horkheimer y Adorno), es el contexto en que se despliega el discurso de José Martí y que se debe considerar para comprender tanto su obra en general como este fragmento en particular.

Samuel Monder propone que Martí utiliza en su Prólogo... "una estrategia argumentativa en la que se reconoce la marca de algunas de las grandes obras de la filosofía moderna" $(2009$, p. 45$)$ y que consiste en una estructura de tres pasos:

se comienza por (a) la descripción de un mundo de opiniones caprichosas, cambiantes y contradictorias en el que nos extraviamos una y otra vez en la búsqueda de la verdad; situación ésta ante la que se propone (b) el repliegue del sujeto sobre sí mismo, buscando respuestas en su interior, analizando sus ideas, evaluando sus capacidades; a lo que sigue (c) el encuentro de un nuevo fundamento en el seno de nuestra interioridad (2009, p. 45).

Así pues, recorriendo un camino similar al de los grandes maestros de la modernidad (Descartes, Hume, Locke), Martí, hijo de su época, sigue una metodología que responde casi a un género discursivo que comienza con lo que retóricamente responde al clásico tópico de la lamentación por los vicios del tiempo presente (acompañado naturalmente por la alabanza a los tiempos idos), que continúa con la consecuente necesidad del sujeto de retirarse ante los peligros circundantes a fin de salvar su alma, y que concluye con la proclamación de un nuevo espacio para la realización interior, en este caso, el de la naturaleza proclamada por el poema de Pérez Bonalde.

El propósito de este artículo es, pues, revisar exhaustivamente el texto del Prólogo... en el orden argumentativo tripartito que se propone más arriba con el fin de comprender el lugar del escritor en la modernidad lati-

\footnotetext{
${ }^{1}$ Prólogo al "Poema del Niágara” de Juan Antonio Pérez Bonalde. Este trabajo se publicó en Nueva York, en 1882, y fue reproducido en la Revista de Cuba, tomo XIV, 1883. En Obras Completas, tomo 7, pp. 223-238.
} 
noamericana según Martí, desprendiéndose de este análisis que es posible deducir, tanto por los comentarios que hace con respecto a las nuevas tareas del escritor sumergido en las urgencias vertiginosas del tiempo nuevo como por la praxis escritural misma de Martí, que esa modernidad incómoda supone para el escritor un rostro bifronte: por un lado, el poeta iluminado por la revelación que roba a su encuentro con la naturaleza y, por otro, el cronista que, desde la prensa, dispara su artillería discursiva. Desde ambos frentes, el escritor procura espacios relativamente autónomos que le concedan libertad para vivir su compromiso con los valores que propugna.

\section{RUINES TIEMPOS}

Anafóricamente, las sentencias de Martí sobre su tiempo lo caracterizan como "ruines" (Martí, on-line)2. Son tales porque en ellos, "son mérito eximio y desudado el amor y el ejercicio de la grandeza", porque los hombres ahora "se prendan de las virtudes cuando las ven encomiadas por los demás", pero cuando ven que la virtud "tiene forma de cruz, la echan de sí con espanto”. “'Ruines tiempos, en que los sacerdotes no merecen ya la alabanza ni la veneración de los poetas, ni los poetas han comenzado todavía a ser sacerdotes! Tiempos en que el poeta "ha mudado de labor, y anda ahogando águilas". Ha quedado "en desuso la lírica pagana" y también la lírica cristiana que, en otro tiempo, "fue hermosa". No hay lugar ni para la lírica ni para la épica, porque no hay lugar para el sosiego. "Todos son soldados del ejército en marcha. A todos besó la misma maga. En todos está hirviendo la sangre nueva, en su rincón más callado están, airadas y hambrientas, la Intranquilidad, la Inseguridad, la Vaga Esperanza, la Visión Secreta". La maga feroz, visión inversa del hada madrina de los buenos cuentos, contrahecha versión de la musa antigua, ha tocado a los poetas de hoy con la náusea del vivir transitorio, con el desequilibrio que produce la máquina acechante y aniquiladora del progreso que todo lo intenta y que todo lo desecha: "No hay obra permanente, porque las obras de los tiempos de reenquiciamiento y remolde son por esencia mudables e inquietas; no hay caminos constantes, vislúmbranse apenas los altares nuevos, grandes y abiertos como bosques". En este escenario cambiante, "en este desconcierto de la mente, en esta revuelta vida sin vía fija, carácter definido, ni término seguro, en

\footnotetext{
${ }^{2}$ Todas las citas del Prólogo... se señalan entre comillas y corresponden a la versión citada en Referencias bibliográficas, revisada on-line.
} 
este miedo acerbo de las pobrezas de la caza", no son posibles "aquellas celosas imitaciones de gentes latinas que se escribían pausadamente, año sobre año, en el reposo de la celda, en los ocios amenos del pretendiente en corte, [...], en la beatífica calma que ponía en el espíritu la certidumbre de que el buen indio amasaba el pan, y el buen rey daba la ley, y la madre Iglesia abrigo y sepultura", puesto que "[s]ólo en época de elementos constantes" son posibles "esas macizas y corpulentas obras de ingenio que requieren sin remedio tal suma de favorables condiciones". He aquí, entonces, el diagnóstico principal: las circunstancias de un tiempo cambiante hacen imposible la proliferación de la gran literatura de antaño.

Y así como no hay obras permanentes, tampoco hay "ideas permanentes". Antiguamente, el repositorio de las grandes ideas eran los grandes poemas, la inmutable tragedia, la epopeya. Hoy, en cambio, el lugar de las ideas es "el periódico". Pero, así como "los ferrocarriles echan abajo la selva; los diarios la selva humana". "El periódico desflora las ideas grandiosas". "Las ideas no hacen familia en la mente, como antes, ni casa, ni larga vida". Las ideas llevan la velocidad del caballo y del relámpago, crecen no en el caldo de cultivo de la madurez del genio individual, sino en el arbitrio y el comercio de la colectividad y la cotidianidad profanadoras que las toman, las "estrujan", las "ponen en alto", las "vuelcan", "las mantean”... y así, no hay buen fruto que esperar. No hay tiempo para germinación y brote natural alguno, pues "[c] on un problema nos levantamos; nos acostamos ya con otro problema". "No alcanza el tiempo para dar forma a lo que se piensa". Lo que surge, finalmente, son "pequeñas obras fúlgidas [y no] aquellas grandes obras culminantes, sostenidas, concentradas".

Julio Ramos sintetiza esta parte del Prólogo... de Martí como "una reflexión sobre los problemas de la producción e interpretación de textos literarios en una sociedad inestable, propensa a la fluctuación de los valores que hasta entonces habían garantizado, entre otras cosas, el sentido y la autoridad social de la escritura" y como "una meditación sobre el lugar impreciso de la literatura en un mundo orientado a la productividad, dominado por los discursos de la modernización y el progreso" (Ramos, 2009: 48). Plantea, además, que este texto, como en general los prólogos de fines del siglo XIX, "casi siempre [...] están marcados por la nostalgia correspondiente a lo que Darío llamaba la pérdida del reino", lo que reafirma la presencia del tópico de la alabanza del tiempo ido, revelando así "la crisis del sistema cultural anterior" (Ramos, 2009, p. 48). Se trata, en efecto, de una crisis de sistema, probablemente la más fecunda en la historia de las letras americanas, pues encuentra a una generación madura de intelectua- 
les (Martí, Darío, Gutiérrez Nájera, Rodó, etc.) capaces de poner en acto una propuesta que incidiría en el escenario cultural tanto americano como europeo.

Semióticamente dicha crisis es representada por Martí con una serie de opuestos que conviene resaltar: Ferrocarril-selva natural (devastación de la naturaleza en beneficio de la técnica), periódicos-selva humana (invasión de nuevos mecanismos de producción cultural amenazantes por su fragmentarismo e inmediatez), ideas en la antigüedad-ideas en la modernidad (desarrolladas con respeto y lentamente las primeras; con pragmatismo y apresuradamente, las segundas), tiempo de las vallas alzadas-tiempo de las vallas rotas (nuevamente la oposición entre la época arcádica de la integración en contraposición con la tensión de la fragmentación presente). Esta crisis, para Julio Ramos, coincide con "lo que M. Weber llamaba el desencantamiento del mundo", es la materialización de los procesos de "racionalización y secularización" de la modernidad y tiene efectos que Martí "directamente relaciona con la ineficacia de las formas y el desgaste de los modos tradicionales de representación literaria" (Ramos, 2009, p. 50).

Domínguez Rubalcava reflexiona sobre el rol del escritor en la modernidad, señalando su particular condición como época "contradictoria y plural". En ese sentido cita a Octavio Paz quien comprende "la tradición moderna como una tradición de rupturas" y, al decir de Paz, como "[u]na tradición hecha de interrupciones y en la que cada ruptura es un comienzo... la modernidad nunca es ella misma: siempre es otra. Lo moderno no se caracteriza únicamente por su novedad, sino por su heterogeneidad" (Paz 1982, pp. 17-18, citado por Domínguez, 2001, p. 14). Esta circunstancia produce efectos en el sujeto que, "ya no pertenece orgánicamente a una tradición, el sujeto se ve de manera inevitable desprendido de lo que lo antecede y se encuentra libre para dirigirse a cualquier punto de fuga" (Domínguez, 2001, p. 15).

\section{REPLIEGUE DEL POETA}

Cabe indicar de partida que Martí no defiende en su Prólogo... el intimismo romántico del poeta, sino una retirada necesaria por mientras "la vida se asiente", es decir, mientras dura el movimiento desequilibrador. Así pues, cuando todo esté en calma nuevamente, cuando se reordenen las fuerzas dispersas por el caos, "surgirá el Dante venidero". Mientras tanto, "[h]oy Dante vive en sí, y de sí". Exiliado de la "polis", al decir de Ramos (2009: 
50), el poeta, según Martí, se afinca en un nuevo espacio: "La batalla está en los talleres; la gloria, en la paz; el templo, en toda la tierra; el poema, en la naturaleza". Sin embargo, este ejercicio de "hallarse a sí mismo" no está exento de un gran trabajo: "El hombre, apenas entra en el goce de la razón que desde su cuna le oscurecen, tiene que deshacerse para entrar verdaderamente en sí". Debe luchar hercúleamente "contra los obstáculos que le alza al paso su propia naturaleza", debe desentenderse de "la vida pegadiza y postadquirida" para abrazar "la espontánea y prenatural". Coincidiendo casi con el nihilismo nietzscheano, debe dejar atrás las ataduras que desde la cuna le han impuesto "las filosofías, las religiones, las pasiones de los padres, los sistemas políticos", para acoger "la verdadera vida [que] viene a ser como corriente silenciosa que se desliza invisible bajo la vida aparente". La verdadera reconquista de sí debe "asegurar el libre albedrío humano", la "libertad espiritual"; sin ellos no hay ni "originalidad literaria" ni "libertad política"

\section{LA NATURALEZA, EL NUEVO FUNDAMENTO}

La tercera parte del Prólogo... apunta, entonces, a ofrecer la propuesta de Martí. El nuevo fundamento y el establecimiento de la nueva libertad está $\mathrm{n}$ en el encuentro con la naturaleza, después del despojamiento de todo lo adquirido. Las palabras del poeta cubano recuerdan nuevamente a Nietzsche, $\mathrm{y}$ también a Rousseau, al decir que

[t] oca a cada hombre reconstruir la vida: a poco que mire en sí, la reconstruye. Asesino alevoso, ingrato a Dios y enemigo de los hombres, es el que, so pretexto de dirigir a las generaciones nuevas, les enseña un cúmulo aislado y absoluto de doctrinas, y les predica al oído, antes que la dulce plática de amor, el evangelio bárbaro del odio. [...] ¡El poema está en el hombre, decidido a gustar todas las manzanas, a enjugar toda la savia del árbol del Paraíso y a trocar en hoguera confortante el fuego de que forjó Dios, en otro tiempo, la espada exterminadora!

Martí está hablando de un hombre que se atreve a regresar a la matriz fundante de su existencia. Es un proyecto titánico de desfondamiento radical que desdice las prácticas circunstantes a su época, ejecutadas por artífices del nuevo poder que son capaces de atravesar la Tierra entera sin

\footnotetext{
${ }^{3}$ Todas las citas corresponden a Martí, on-line.
} 
obstáculos, que conocen el secreto de la locomotora y de la telefonía, que rearman las relaciones sociales, políticas y laborales con el arte de la industria, pero que no conocen el secreto de su propia índole inaugural. Aquellos hombres son pasajeros superficiales del progreso que pasan por todo, atropellándolo todo -naturaleza, sociedades, seres humanos- sin comprender el más mínimo misterio. A cambio de todo ello, el "Poema del Niágara" representa para Martí lo que vale de verdad:

Lo que el Niágara cuenta; las voces del torrente; los gemidos del alma humana; la majestad del alma universal; el diálogo titánico entre el hombre impaciente y la naturaleza desdeñosa; el clamor desesperado de hijo de gran padre desconocido, que pide a su madre muda el secreto de su nacimiento; el calor divino que enardece y encala la frente del hombre a la faz de lo grandioso; la compenetración profética y suavísima del hombre rebelde e ignorador y la naturaleza fatal y reveladora, el tierno desposorio con lo eterno y el vertimiento deleitoso en la creación del que vuelve a sí el hombre ebrio de fuerza y júbilo, fuerte como un monarca amado, ungido rey de la naturaleza ${ }^{4}$.

\section{LA LEY CONTESTADA}

Para comprender cómo la literatura, y en particular los nuevos géneros que cultiva el escritor finisecular, está inscrita en un nuevo orden, es necesario atender al hecho de que Martí propone una discusión frente a la ley establecida por el canon latinoamericano decimonónico. Según Ramos, "al leer a Sarmiento y a Bello, la formalización de la ley había sido una de las tareas claves de los intelectuales patricios, dominados, como han señalado Claudio Véliz y especialmente Ángel Rama, por el modelo renacentista del letrado" (2009, p. 51). Ese proyecto, fundado desde la centralidad hegemónica del escritor y concomitante con el discurso del poder, "se relaciona ahí con los 'legados y ordenanzas [de] los que antes han venido', es decir, con el peso de la tradición represiva que dificulta tanto la 'libertad política' como la 'libertad espiritual'"(Ramos, 2009, p. 51). Pero, en tiempos de 'vallas rotas', al poeta se le han quitado sus posesiones y su nombradía. Su posición

\footnotetext{
${ }^{4}$ Profundizar en esta cuestión requiere leer detenidamente el artículo de Monder, en el cual se plantea que "Martí maneja un doble concepto de naturaleza: por una parte, se trata de una fuerza que actúa de acuerdo con leyes poéticas precisas (leyes que habrán de ser descubiertas por poetas); por otra parte, es un poder disruptivo que sistemáticamente destruye cualquier sistema que construyamos para encapsular sus productos" (Monder, 2009, p. 43).
} 
de desterrado le confiere un nuevo lugar en el orden discursivo, separándolo por lo que Foucault llama procedimientos o principios de exclusión (El orden del discurso). Martí tiene la claridad para comprender que el lugar del poeta de los tiempos modernos (su propio lugar) tiene que asumir esa exclusión, so pena de convertirse en un servidor de la ley, dominado por los atavismos de un orden en el que no cuenta su palabra destructora. Por eso, "[p]ara Martí el poeta es un desterrado de la ley y la literatura el 'clamor desesperado de hijo de gran padre desconocido, que pide a su madre muda [la naturaleza] el secreto de su nacimiento" (Ramos, 2009, p. 51). En ese contexto, la literatura se convierte para él en un "discurso crítico de los códigos y de la ley misma" (Ramos, 2009, p. 51). Martí podría haber acudido a las imágenes del "loco" de Foucault o del poeta que, antes de Platón, representaba "el discurso verdadero por el cual se tenía respeto y terror, aquél al que era necesario someterse porque reinaba" (Foucault, 1992, p. 9). Sin embargo, según Ramos, la imagen que mejor acomoda es la de Ismael, el hijo natural, negado y desterrado por su padre Abraham. Como él, "el escritor es un desplazado de la institución paterna, un exiliado de la polis" (2009, p. 51).

Así pues, ha de entenderse que la producción literaria modernista y, en particular, la "crónica modernista", asume esta locación marginal para cuestionar, desde un campo literario cada vez más autónomo, el orden imperante. De algún modo, el escritor modernista aprovecha la periferia en que el sistema de exclusión lo ha colocado para erigirse como una voz permanente, como una conciencia estética que apelando a lo bello de "antaño" denuncia la fealdad de "hogaño". La "nostalgia de la hazaña" refuerza en él su asco y desconfianza frente a este escenario de ruinas (al decir de Benjamin) y, aunque habitante de la misma urbe y usufructuario de los mismos beneficios de la modernidad, se manifiesta como un testigo del pasado heroico, venido a sembrar las semillas de un utópico devenir. Modernista, por lo tanto, desde esta perspectiva, no debería asimilarse a la noción popular que ha adquirido con los años y que lo ha acercado más a una cierta concepción de "enajenación", “distanciamiento" y olvido del presente. La "Torre de marfil" de Darío exige ser resignificada como la atalaya crítica desde la cual el escritor modernista observa su presente circundante, refugiándose en la convicción de una belleza que, allá lejos en el pasado o en territorios remotos, sigue reclamando la voz del poeta. No otra cosa hizo en su momento Cervantes, por ejemplo, cuando lamentando la decadencia del siglo XVII español, coloca en boca de su Quijote el discurso de la "Edad Dorada". Ejemplo de que, en Martí, esta mirada al pasado no tenía un simple carácter 
nostálgico y que su añoranza de la hazaña no quedaba en una contemplación pasiva, es el proyecto pedagógico que precisamente tituló "La edad de oro" y que consistió en una revista infantil destinada a formar a los niños en los grandes ideales y en la conciencia americana de sus próceres ${ }^{5}$.

\section{POETA Y CRONISTA: DOS OFICIOS DISTINTOS PERO UN SOLO ESCRITOR NOMÁS}

El modernismo, en palabras de Federico de Onís, es "la forma hispánica de la crisis universal de las letras y del espíritu que inicia, hacia 1885 , la disolución del siglo XIX y que se había de manifestar en el arte, la ciencia, la religión, la política y gradualmente en los demás aspectos de la vida entera" (De Onís, 1968, p. 183). Esta definición amplia permite comprender que, más que una escuela literaria, el modernismo responde a un espíritu epocal que, desde distintas manifestaciones culturales, muestra características de elitismo aristocrático, crítica a la burguesía, esteticismo refinado y a veces rebuscado, retórica trabajada en la ironía e incluso en la sátira, incursión en temáticas orientalistas y recurso frecuente al pasado, redescubrimiento de la tradición americanista e incluso contribución a la creación del mito "americano", etc. Sin duda, hay una necesidad de diferenciación entre el intelectual modernista que, distanciándose del pragmatismo positivista en uso, se esfuerza por materializar en "el estilo" su marca cultural.

Por cuanto concierne a los escritores modernistas latinoamericanos, es importante destacar la influencia que tuvieron Manuel Gutiérrez Nájera (mexicano), José Martí (cubano), Rubén Darío (nicaragüense), Leopoldo Lugones (argentino), Enrique Larreta (argentino), José Asunción Silva (colombiano), Julián del Casal (cubano), Enrique Gómez Carillo (guatemalteco), Amado Nervo (mexicano), Delmira Agustini (uruguaya), José Enrique

5 "La Edad de Oro fue una revista mensual dedicada al recreo y la ilustración de los niños, que empezó a publicar José Martí en Nueva York en el mes de julio de 1889 y de la cual sólo se publicaron cuatro números. Esta revista nos permite ver cómo aquel gran escritor supo un día dirigirse también a los más pequeños. En carta a Mercado de agosto de 1889, dijo Martí de esta revista: "ha de ser para que ayude a lo que quisiera yo ayudar, que es a llenar nuestras tierras de hombres originales, criados para ser felices en la tierra en que viven, y vivir conforme a ella, (...). La revista contenía cuentos, versos y artículos instructivos, como ‘Tres Héroes', en que Martí presenta a los niños tres de los grandes patriotas de nuestra América: Bolívar, San Martín e Hidalgo; 'Las Ruinas indias', donde describe de forma inigualable las ciudades desaparecidas de la América indígena; 'El Padre las Casas', en que hace un estudio admirable del gran defensor de los indios". (Memorial José Martí on-line).

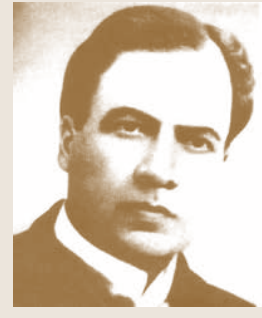

R. Darío

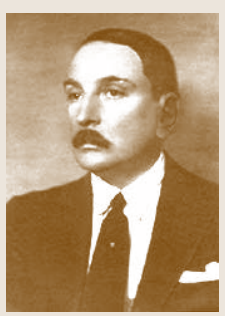

E. Larreta 


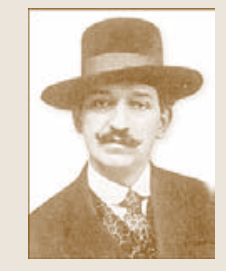

E. Gómez Carrillo

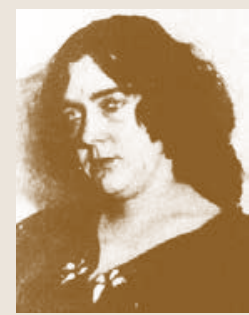

D. Agustini

Rodó (uruguayo), etc. El influjo del modernismo atravesó fronteras y llegó hasta España, siendo, probablemente, el primer movimiento cultural que atravesó el Atlántico de vuelta después de cuatro siglos desde la conquista de América.

Entre ellos, fue bastante común el cultivo simultáneo de distintos géneros. En algunos, la poesía, en otros la novela y el cuento... y, en la mayoría, el ejercicio de la crónica periodística. La coexistencia de ambas prácticas escriturales se explica, en primer lugar, por la necesidad de legitimación que los escritores buscaban en los periódicos, en el contexto de la emergente cultura de masas. También es recurrente la explicación relacionada con la necesidad de los escritores (ya sin mecenas ni protección alguna) de encontrar un sustento suplementario a los escasos réditos que les producían sus creaciones literarias. Sin embargo, más allá de dichas razones, es fundamental destacar que es precisamente en la crónica donde el escritor modernista tuvo la oportunidad de comunicar día a día su visión de mundo y, a través de ella, dar evidencias de que el modernismo, a pesar del retraimiento del poeta del que habla Martí, tiene su lugar en la ciudad. El escritor modernista no se recluye en un palacio o en un convento, sino que revisita permanentemente, como un flâneur consciente de su autonomía, los espacios urbanos, en constante inmersión en el hálito de la muchedumbre. "El yo que Martí anuncia como respuesta a la modernidad, a la crisis finisecular, no es confesional o personalizado: es un yo que quiere asumir en sí el universo, un yo colectivo que no expresa la individualidad sino el alma del mundo" (Rotker, 2005, p. 144). En este sentido, cobra importancia el comentario de Ramos con respecto a que, a través de la crónica, "la literatura representa, a veces ansiosamente, en el periódico, su encuentro y su lucha con los discursos tecnologizados y masificados de la modernidad" (Ramos, 2009, p. 55). Así, pues, Ramos propone no leer la crónica "como una forma meramente suplementaria de la poesía, ni como un simple modus vivendi de los escritores [sino más bien que] la heterogeneidad de la crónica, la mezcla y choque de discursos en el tejido de su forma, proyecta uno de los rasgos distintivos de la institución literaria latinoamericana" (Ramos, 2009, pp. 55-56).

Claudia Darrigrandi destaca que el "sentimiento de celeridad, que se irradió en más de un ámbito de la vida de fin de siglo, fue también un dispositivo para la producción de un género, en el que dejó su impronta, tanto en su forma como en su contenido" (Darrigrandi, 2013, p. 128); cita al argentino Manuel Ugarte, quien dice que en "París no hay una novedad cada veinticuatro horas, sino veinticuatro novedades por hora" (Darrigran- 
di, 2013, p. 128). En la misma línea, Susana Rotker comenta que "El prólogo de José Martí al 'Poema del Niágara' [...] es un texto fundador porque la temporalidad -entendida como la conciencia del tiempo en que se vive- es su propuesta estética" (2005, p. 139). Andrew Reynolds destaca que dicha conciencia de vertiginosidad se advierte en las primeras palabras del Prólogo, cuando Martí exclama: “Pasajero, detente!” (Cfr. Reynolds, 2012, p. 73). Como nos recuerda el mismo Reynolds, Aníbal González había planteado que la temporalidad es "una preocupación constante" en el género crónica (Cfr. Reynolds, 2012, pp. 73-74). Estas consideraciones nos hacen volver nuevamente al texto de Martí para subrayar sus insistencias con respecto a su preocupación por "los ruines tiempos" en los términos que fueron destacados anteriormente.

La condición propia de la época diagnosticada por Martí, de "celeridad", "simultaneidad", de "inmediatez de lo humano", urge al intelectual moderno presentar "nuevas respuestas" (Cfr. Rotker, 2005, p. 141). En tal panorama de dispersión, la crónica no puede sino ser apurada, improvisada, fragmentaria, plurivocal, y abocada a las más variadas temáticas.

Susto y deleite implican que en la percepción del mundo se trasluce la duda, la transición, el asombro. Las tradiciones institucionales resultan insuficientes para comprender la vida en su multiplicidad; las ciencias no aclaran sino parcialmente la dimensión física; y la metafísica, especialmente la ontología, es la rama más lesionada de la modernidad. [...] Las formas debían acompañar los procesos de elaboración de los tiempos modernos. No había verdades como templos: había parcialidades generadoras de otras, había urgencias por comprender a las que cada día se agregaba un dato diferente. Por eso concluye José Martí [...] que el lugar de las Ideas era el periodismo: el espacio de lo no permanente, de la comunicación, del aporte del dato actualizado, de los públicos mayoritarios, de inquirir y no establecer (Rotker, 2005, pp. 141-142).

"El lugar de las ideas era el periodismo". A nuevos tiempos, nuevas formas y el escritor modernista debe responder a ellos sin eludir su responsabilidad y las exigencias que ellos le imponen. He aquí que coexistan sin contraposición su condición de poeta y de cronista. Sin embargo, creo ver en la naturaleza misma del sujeto crítico, sometido a los embates de la modernidad, un esfuerzo que proviene de una agonía dramatizada por la necesidad de asumir la muerte de una época y de los procedimientos que en la producción estética le correspondían. Dicho proceso se remonta a las preguntas que se hizo Baudelaire en Francia sobre cómo el poeta puede 
serlo en la modernidad, y que son, de algún modo, las que Martí se hizo en América. En efecto, Baudelaire se plantea la gran interrogante sobre cuál es el destino que puede alcanzar la poesía en una civilización comercializada y dominada por la técnica. La tradición, entonces, de la poesía moderna, arranca del reenquiciamiento epocal requerido por las grandes transformaciones que el mundo occidental impulsó. Los que vivieron en profundidad ese desafío y acataron su llamado, refacturaron su oferta ya no desde una simple óptica de género (el cronista, el novelista, el poeta) sino desde una posición enunciativa que les exigía, en un momento, ser poetas, y en otro, cronistas.

Ahora, bien, la crónica modernista, diferenciada de la crónica de Indias y de la crónica contemporánea (Cfr. Darrigrandi, 2013) recoge, en sí y de la manera más representativa, lo que el escritor moderno estaba llamado a ser. Fragmentación, temporalidad, encuentro de discursos, participación receptiva de las masas lectoras, cruces estilísticos entre prosa y verso, encuentro de literatura y periodismo, etc.; todo ello confirma que "la elección de la crónica como escritura está muy lejos del torremarfilismo y de la marginación lujosa de la sociedad" (Richard Homan, citado por Rotker, 2005, p. 134).

\section{ORIGINALIDAD LITERARIA Y LIBERTAD POLÍTICA}

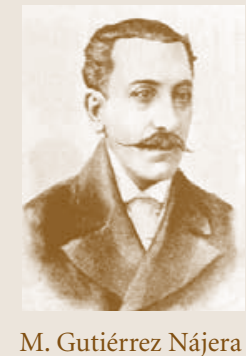

M. Gutiérrez Nájera
Para entender los alcances que la crónica tiene para Martí, es necesario hacer una breve revisión comparativa entre él y Manuel Gutiérrez Nájera. La elección no es gratuita, pues ambos están en el origen de la crónica modernista latinoamericana, tanto por ser sus primeros exponentes como por prefigurar dos estilos que, siendo cercanos en algunos aspectos, se distancian en otros.

... el trasplante del género de la chronique a Hispanoamérica se atribuye, en primer lugar, al mexicano Manuel Gutiérrez Nájera, seguido muy de cerca, en términos cronológicos, por José Martí. Podríamos decir que a Nájera le toca introducir el género y a Martí el darle mayor relieve intelectual y difusión continental. Las primeras crónicas de Nájera y de Martí aparecen hacia 1880: las de Nájera, en El Nacional, de México, y las de Martí, en La Opinión Nacional, de Caracas (González, 1983, p. 77).

Siguiendo a Aníbal González, es posible sintetizar algunas diferencias interesantes entre ambos cronistas. A saber: a) el estilo de Nájera era "muy 
cercano al de sus modelos franceses: ligero, mundano, luciendo a veces una frivolidad afectada" (1983, p. 77), mientras que el de Martí era "más personal: arcaizante, sentencioso, oratorio, nunca frívolo" (1983, p. 78); b) Nájera utilizó, en su carrera de veinte años en el periodismo, varios seudónimos, mientras que Martí "siempre firmó sus artículos" (1983, p. 78), lo cual da luces de que Nájera resolvió la problemática de la fragmentación del yo enunciativo de la crónica de esa manera, mientras que Martí "se propuso imponer la coherencia de su 'yo' y de una voz poética potente, uniforme y original" (1983, p. 79); c) probablemente, para Nájera, la crónica era un género que se ubicaba en la "encrucijada entre el periodismo y la literatura", mientras que, para Martí, era "el vehículo para la constitución de una obra (no sólo, tal vez, en el sentido mallarmeano del Libro -que Martí hubiese reprochado-, sino en el doble sentido que se cifra en esta palabra: libro y acto)" (1983, p. 78); d) si bien parece que Nájera da cuenta más transparente de la fragmentación de la modernidad en sus crónicas, "Martí, quien disciplinó y dio su vida al servicio de un ideal, buscó además en todo momento integrar la diversidad caótica de datos que le ofrecía la realidad en un todo armónico" (1983, pp. 78-79); e) la crónica de Nájera es más difusa con respecto a las temáticas políticas, "a diferencia de Martí, cuyo ideario estaba siempre presente en sus escritos" (1983, p. 98), lo que da cuenta, más allá de sus intereses, probablemente de un espacio autónomo menos generoso para Nájera (su familia dependía de él) que para Martí quien había sido dotado de un "don de sacrificio" no exigible a Nájera (según Carter, comentado por González, 1983, p. 99).

Esta serie de diferencias entre los primeros cronistas modernistas, no obstante la amistad que los unía, señala dos paradigmas en el concurso del lugar que cada cronista considera que debe ocupar en el mapa social y el grado de compromiso que puede asumir con respecto a su discurso. Evidentemente, debido al posicionamiento crítico del escritor en la crónica frente a las cuestiones de su tiempo y a las contingencias locales más inmediatas, ésta debió de ser una cuestión que les preocupaba. Ambos participan de situaciones políticas complicadas: la dependencia de la Cuba de Martí ante España y el Porfiriato (1876-1911) en el México de Nájera. Este supo negociar con su tensión en forma moderada aunque no menos honesta; Martí, en cambio, optó por la vía trágica del heroísmo que lo llevó incluso a morir en el campo de batalla por la independencia de Cuba.

Estas consideraciones remiten necesariamente a una de las sentencias del Prólogo... de Martí: "Ni la originalidad literaria cabe, ni la libertad política subsiste mientras no se asegure la libertad espiritual". De aquí, enton- 
ces, que cabe considerar que "su nostalgia de la hazaña", su búsqueda de las voces de la naturaleza y todo su proyecto confluyen en el todo unitario y sacrificial que significó la movilización de sus múltiples recursos en función de un único ideal. El resultado de esta empresa ya no es posible verlo como la suma de una serie de discursos aislados o la escindida producción del poeta y del cronista. Más que eso, Martí se constituye en una voz poderosa que refleja la coherencia de su visión frente al mundo de ruinas, vertiginoso, cambiante, voluble, que le había tocado contemplar y vivir. Una voz tan potente que Paul Groussac mismo dijo: "[e]n Español nada hay que se parezca a la salida de bramidos de Martí", comparándolo con Víctor Hugo, de quien nadie, a esas alturas (1887) había podido reproducir en Francia su "resonancia de metal" (citado por González, 1983, p. 79).

\section{CONCLUSIONES}

La modernidad latinoamericana supuso un replanteamiento del lugar del intelectual y del escritor en la cultura latinoamericana en la segunda mitad del siglo XIX. El modelo cultural del letrado, inspirado en la lógica de Port Royal, el "bien decir" y el arte de pensar, anclados en un racionalismo ordenador cartesiano, entran en crisis con el vaivén vertiginoso de nuevos decires que surgen como propuesta contra un orden monolítico que terminaba cediendo a la fragmentación, la prisa, la novedad, la conciencia de un tiempo evanescente. En este contexto, el Prólogo de José Martí a "El poema del Niágara" (1882) resulta ser un documento imprescindible para comprender la radicalidad de dicha crisis y el nuevo lugar del escritor en la modernidad.

El Prólogo..., tal como lo asevera Samuel Monder, contiene tres partes: a) Diagnóstico de los tiempos presentes, calificado con el adjetivo de "ruines" por Martí, en donde todo resulta provisorio y en donde ya no son posibles las grandes obras de antaño. En contraposición, un nuevo género aparece: "la crónica", que habla del consorcio que la literatura mantendrá durante décadas con el periodismo. b) El despojamiento del poeta de todo lo adquirido, retraimiento necesario para replantearse ante la búsqueda de un nuevo fundamento. c) El encuentro con la naturaleza como espacio de refundación, entendida ésta en su profundidad antropológica y como dinámica esencial del ser. A esa naturaleza, el poeta interroga sobre el secreto de su nacimiento, desde su condición de "exiliado de la polis". 
Martí se propone identificar con su búsqueda la necesidad que el poeta tiene de "libertad espiritual", puesto que sólo con ella son posibles la "originalidad literaria" y "la libertad política". De este modo, se configura el perfil de un escritor nuevo que, desterrado de la centralidad que en algún momento tuvo en la ciudad letrada, debe escribir, desde su condición de excluido, su amarga profecía. Lo hará teniendo presente una permanente dialéctica con respecto a la ciudad moderna, es decir, un juego de alejamiento y de acercamiento, un estar dentro de ella sin ser completamente suyo, dinámica de presencia constante pero sin perder la conciencia autoconfiguradora de un yo progresivamente autónomo. Por este motivo, al ojo avizor de su poesía le corresponderá el tono crítico de sus crónicas. He ahí, de algún modo, el proyecto modernista en su esencial posicionamiento frente al mundo.

De entre la gran mayoría de los escritores de entresiglos que cultivaron, junto a sus creaciones literarias, la crónica periodística, destacan las figuras de Manuel Gutiérrez Nájera y de José Martí. Primero, por ser sus fundadores en Latinoamérica y, segundo, por representar dos modelos a tener en cuenta al mirar la histórica de la crónica en el siglo XX. El primero, elegante, refinado, culto, ligeramente afrancesado, como cultor de una crónica que, siendo crítico a la modernidad, actúa con respeto frente a la escasa autonomía que le ofrecen sus obligaciones familiares y las circunstancias políticas que lo determinan (el Porfiriato, en su caso). El segundo, más sencillo y esencial en su prosa, se muestra abiertamente comprometido por la urgencia de una causa que lo involucra incluso al punto de poner en peligro la integridad de su yo personal.

Tal vez, para leer la mayor parte de los cronistas modernistas, servirá más el modelo de Nájera, pues en ellos se hacen presente las negociaciones que el escritor debe hacer con su circunstancia a fin de no ser destruidos en su proyecto. El caso de Martí, en cambio, representa un compromiso aniquilador con la verdad y con sus atronadoras consecuencias; quizás al modo de Mariátegui o del mismo Zola con su J'accuse.

La postura de Martí y la honestidad de su palabra es materia que asombra por su inagotable vigencia, sobre todo ahora, en tiempos en que, como entonces, los intereses personales o grupales parecen haber cedido a los principios erigiendo la hipocresía como estrategia de salvamento. La "nostalgia de la hazaña" se traduce en sentimiento de dolor por el "paraíso perdido", por la edad dorada quijotesca, por el buen caballero que fue don Rodrigo Manrique y que su hijo honra en sus famosas coplas. Con respecto 
a esta crisis de valores, Susan Sontag, en un diálogo con Tony Kushner, afirma:

Tengo la impresión de que la mayoría de la gente ve muy ajena, casi incomprensible, la idea de que tú puedes hacer algo desinteresado, al margen de los estímulos financieros o del grado de molestias o dificultades o del peligro personal: "Mis principios me dictan..." o "Mis principios me prohíben..." o "Como creo que es lo correcto, es lo que voy a hacer", o "Debo hacerlo aunque sea riesgoso...", este tipo de lenguaje, de pensamiento, ya agoniza (citado por Monsiváis, 2004, p. 28).

Sin embargo, esta agonía no es nueva, ni lo fue solamente en tiempos de Martí. Es de todo pasado en que se recuerde la palabra descontenta de algún poeta que haya tenido la percepción de que su escritura era la única carta con la que podía acusar los sordos poderes dominantes, proteica sustancia humana que asola los pueblos abrigándose en dispositivos imbricados en urdimbres institucionales complejas.

Por esto, cuando en su Prólogo... Martí habla de la búsqueda del poeta de su interioridad a través de la naturaleza, se adivina que está apuntando precisamente a esa identidad esencial que está en el origen de la condición humana, previa a la construcción dada por los sistemas postadquiridos (la religión, los códigos, las ideologías). En definitiva, se trata del encuentro con la existencia previa a la "ley", no para cuestionar caprichosamente la ley imperante, sino para recuperar la libertad interior necesaria para inaugurar un futuro radicalmente instalado en la utopía de un orden hecho a la medida generosa de la vocación humana y de sus permanentes reclamos. De ahí, entonces, que la palabra del poeta y cronista modernista no se detenga solamente en la "denuncia", sino que, por sobre todo sea un "anuncio" de la profecía de la belleza y de la justicia, dimensiones propias que fecundaron el imaginario del siglo XX y sembraron la semilla de las poderosas escrituras latinoamericanas. Así se entienden los términos en que Gabriel García Márquez, justo un siglo después del Prólogo... de Martí, se refiere a su vocación de escritor apelando al compromiso de la palabra escrita, representada simbólicamente como "poesía":

En cada línea que escribo trato siempre, con mayor o menor fortuna, de invocar los espíritus esquivos de la poesía, y trato de dejar en cada palabra el testimonio de mi devoción por sus virtudes de adivinación, y por su permanente victoria contra los sordos poderes de la muerte. El premio que acabo de recibir lo entiendo, con toda humildad, como la consoladora revelación de que mi intento no ha sido en vano. Es por eso que invito 
a todos ustedes a brindar por lo que un gran poeta de nuestras Américas, Luis Cardoza y Aragón, ha definido como la única prueba concreta de la existencia del hombre: la poesía (García Márquez, 1982, on-line).

\section{REFERENCIAS}

Darrigrandi, C. (2013). "Crónica latinoamericana: algunos apuntes sobre su estudio". Cuadernos de Literatura, XVII(34), julio-diciembre, 122-143.

De Onís, F. (1968). "Historia de la poesía modernista". España en América. Puerto Rico: Universidad de Puerto Rico.

Domínguez Rubalcava, H. (2001). La modernidad abyecta. Formación del discurso homosexual en Hispanoamérica. Xalapa: Biblioteca Universidad Veracruzana.

Foucault, M. (1992 [1970]). El orden del discurso. Buenos Aires: Tusquets Editores.

García Márquez, G. (1982). "La soledad de América Latina”. Discurso de aceptación del Premio Nobel de Literatura. http://www.ciudadseva.com/textos/ otros/la_soledad_de_america_latina.htm

González, A. (1983). La crónica modernista hispanoamericana. Madrid: José Porrúa Turanzas.

Martí, J. (1882). Prólogo al "Poema del Niágara" de Juan Antonio Pérez Bonalde. Este trabajo se publicó en Nueva York, en 1882, y fue reproducido en la Revista de Cuba, tomo XIV, 1883. En Obras Completas. Tomo 7. Versión electrónica: http://www.josemarti.info/libro/prologo_poema_niagara. html

Memorial José Martí. "La Edad de Oro". http://www.cuba.cu/memorial/laedadde.htm. Revisado 10/01/2015.

Monder, S. (2009). “El sistema de lo disperso: José Martí y el sujeto de la filosofía moderna". Acta Literaria [online], 38, 43-54. ISSN 0717-6848.

Monsiváis, C. (2004 [1984]). "La Ciudad Letrada: la lucidez crítica y las vicisitudes de un término". Prólogo de Ángel Rama: La Ciudad Letrada: Santiago de Chile: Tajamar Editores.

Paz, O. (1982). Los hijos del limo. Ciudad de México: Seix Barral.

Ramos, J. (2009). Desencuentros de la modernidad en América Latina. Literatura $y$ política en el siglo XIX. Caracas: Fundación editorial El perro y la rana.

Reynolds, A. (2012). The Spanish American Crónica Modernista, Temporality and Material culture. Maryland: Bucknell University Press.

Rotker, S. (2005 [1992]). La invención de la crónica. Ciudad de México: Fondo de Cultura Económica. 